\title{
Bemerkung zur Farben- und Skulptur-Veränderung der Cassiden.
}

Von

J. W e i s e.

Wenige unserer kleinen paläarctischen Cassidinen besitzen einen hervorragenden Farbenschmuck, dagegen dürfte man die grölseren Arten der subtropischen und tropischen Zone getrost neben die prächtigsten Käfer aus anderen Familien stellen. Die Oberseite dieser vorherrschend grünen Thiere ist mit einem starken bläulichen Silber- oder Perlmutterglanze, oder einem grünlichen bis kupferigen Goldglanze bedeckt, so dafs die Thiere in der Sonne wie Diamanten funkeln. Schon Herbst sagt, Cassiden 303, von einer solchen Art: "Es ist nicht möglich, ihren herrlichen grasgrünen Goldglanz mit dem Pinsel auszudrücken." Noch weniger also durch Worte.

Bekannt ist, dafs diese prächtige Färbung jahrzehntelang erhalten bleibt, wenn man die Thiere in Spiritus aufbewahrt. Derselbe Effect läfst sich auch auf trockenem Wege mittels Naphtalin erreichen. Herr Dr. Drake z. B. brachte seine Cassidinen aus Paraguay, sämmtlich tadellos gefärbt, in Fläschchen herüber, in denen unter die Papierschnitzel Naphtalin gemengt war. Natürlich müssen diese Fläschchen luftdicht verschlossen sein und dürfen nicht geöffnet werden, weil die Thiere sonst zu schimmeln anfangen.

Gespiefst verlieren die grünen Cassidinen sehr bald ibre Farbe und werden mehr oder weniger bräunlich-gelb. Will man sich nun den schönen Anblick verschaffen, den ein solches Thier im Leben gehabt hat, so mufs man dasselbe aufweichen, am Besten in heifsem Seifenwasser. Dann bemerkt man, dafs nicht nur die ursprüngliche Farbe, sondern auch die entsprechende Skulptur wieder hergestellt wird; denn mit dem Verbleichen geht bei verschiedenen Arten zugleich eine Veränderung der Skulptur Hand in Hand. Als Beispiel empfehle ich die Chirida Aubei Boh., von der Guinea-Küste, Westafrika. Boheman nennt die Flügeldecken derselben mit Recht: "subtiliter, regulariter striato-punctatis", denn er hat eingetrocknete Sammlungs-Exemplare beschrieben (Mon. 3, 195). Nach einem Bade in heifsem Seifenwasser ist das Thier kaum noch wieder zu erkennen. Jede Decke besitzt nunmehr eine breite Längsbinde neben der Naht bis hinter die Mitte, 
einen schmalen, vor der Spitze breiten Saum neben dem Seitendache, beide leuchtend metallisch-maigrün, und eine aufserordentlich grobe Punktirung, für welche in dem oben erwähnten Citate mindestens "fortiter" zu setzen wäre. Die Umgebung jedes eingestochenen Punktes hat sich nämlich tief metallisch-grün gefärbt und ist von einem viereckigen, hellgrünen Saume eingefalst, der wie eine erhabene Leiste erscheint, und der umschlossene Punkt, wie eine nach der Mitte abfallende Grube. Es würden daher diese und verschiedene andere Arten nicht richtig nachzubestimmen sein, wenn sie nach frischen Exemplaren beschrieben würden, weil dann die Skulptur als viel zu grob angegeben wäre.

Feststellung einiger Cassiden-Gattungen.

Von

J. We $i s e$.

A. Mesomphalia.

Boheman untersuchte in dieser Gattung nicht von allen Arten die Klauen und bezeichnete letztere daher durchweg als „divaricati subtus basi unidentati“". (Mon. 1, 219.) Chapuis erkannte richtig, dafs Mes. quadraticollis Boh. einfache Klauen hat, aber er hielt dies nur für "einen neuen Beweis der Unbeständigkeit aller Charaktere" (Genera 11, 395), statt die Gattung herauszuziehen, welche Boheman bereits durch die Gruppen-Ueberschrift: "A. Prothorace latitudine fere triplo breviore" von den übrigen Mesomphalien abgesondert hatte. Ich nenne diese natürliche Gattung

Goniochenia: Prothorax transversim quadratus, lateribus subparallelis antrorsum haud convergentibus. Unguiculi simplici. Patria: Brasilia.

Verwandt ist Mesomphalia: Prothorax transversus, lateribus antice convergentibus. Unguiculi appendiculati.

$\mathrm{Zu}$ Goniochenia gehören Mes. 4-collis, laticollis, difformis Boh. und ëne weiter unten beschriebene Art, ob auch congener und bituberculata Boh., steht dahin, die von Boheman angegebene Körperform spricht dafür. Wagener führte diese Arten in der Bestimmungstabelle, Mitth. Münch. 1881, p. 64-66, in bunter Reihe unter den Mesomphalien auf. 


\section{$2 \mathrm{BHL}$ Biodiversity Heritage Library}

Weise, Julius. 1896. "Bemerkung zur Farben- und Skulptur-Veränderung der Cassiden." Deutsche entomologische Zeitschrift 1896(1), 9-10. https://doi.org/10.1002/mmnd.48018960102.

View This Item Online: https://www.biodiversitylibrary.org/item/103427

DOI: https://doi.org/10.1002/mmnd.48018960102

Permalink: https://www.biodiversitylibrary.org/partpdf/235629

\section{Holding Institution}

Harvard University, Museum of Comparative Zoology, Ernst Mayr Library

\section{Sponsored by}

Harvard University, Museum of Comparative Zoology, Ernst Mayr Library

\section{Copyright \& Reuse}

Copyright Status: Public domain. The BHL considers that this work is no longer under copyright protection.

This document was created from content at the Biodiversity Heritage Library, the world's largest open access digital library for biodiversity literature and archives. Visit BHL at https://www.biodiversitylibrary.org. 